\title{
Leaders
}

\section{Autografting as first line treatment for chronic myeloid leukaemia}

\author{
I O Singer, I M Franklin
}

\begin{abstract}
Interest in autografting for chronic myeloid leukaemia and its clinical relevance has revived in recent years. This followed observations that with various chemotherapeutic regimens it was possible to achieve, temporarily at least, peripheral blood and bone marrow that were Philadelphia negative. Bone marrow or peripheral blood progenitor cells could then be harvested and reinfused following a high dose procedure, hopefully eliminating any residual disease, and resulting in prolonged disease free survival. This ideal has not yet been successfully achieved with current strategies. Recent results indicate that eliminating residual disease with current chemotherapy is not normally achievable. The use of more sensitive technologies such as polymerase chain reaction has revealed persistent disease in most if not all apparently Philadelphia negative cases. This is confirmed by results where disease relapse occurs following transplant in these cases. Despite this, clinically relevant remissions are obtained and further trials are indicated. In this review present treatment is discussed and future strategies, using novel techniques as an adjunct to current treatment, are proposed that might improve on present results or even lead to the elusive goal of cure.

(f Clin Pathol 1998;51:92-95)
\end{abstract}

Keywords: chronic myeloid leukaemia; autografting; $\alpha$ interferon

The initial management of patients who present with chronic myeloid leukaemia (CML) is one of the more complex problems in the treatment of the haematological malignancies. For many years the mainstay of treatment was busulphan, an alkylating agent administered orally, which has gradually been replaced over the past decade by hydroxyurea. During this time $\alpha$ interferon has been shown to prolong the duration of the chronic phase, ${ }^{1-3}$ which neither hydroxyurea or busulphan have been shown to do. A recent study from a French collaborative group suggests that the addition of subcutaneous cytarabine to $\alpha$ inter- feron for 10 days each month for six or nine months may prolong survival further. ${ }^{4}$

In the 1980s it was shown that allogeneic transplantation from a histocompatible sibling donor could cure a proportion of patients with CML. ${ }^{6}$ If a sibling is available, transplantation is considered the treatment of choice and is performed optimally in the first 12 months after diagnosis. Unfortunately, only a minority of patients may benefit from a sibling allogeneic transplant as a donor is available for only one in three patients, and elderly patients or those with intercurrent illnesses may be considered unsuitable for the procedure.

Until relatively recently the use of HLA matched unrelated donors was reserved for the youngest and fittest patients because of the daunting morbidity and mortality of such transplants. However, since the advent of molecular typing for both class I and class II major histocompatibility loci it is possible to select more precisely compatible donors. Evidence is beginning to accrue that patients who receive a bone marrow transplant from an unrelated donor who is fully matched at the molecular level may have the same outcome as if the donor was a histocompatible matched sibling. ${ }^{8}$ However, a proportion of patients will still not have a suitable donor or will be considered unfit to undergo the rigours of an allograft.

\section{The role of autografting}

The concept of using the patient's own haemopoietic stem cells, in the form of an autologous marrow transplant, was developed in the 1970s. Spiers and colleagues at the Hammersmith Hospital in London, UK developed the concept of "perpetual reinduction of chronic phase". They envisaged a situation where chronic phase stem cells would be collected from the blood at diagnosis and stored in liquid nitrogen. At the time of disease progression chemotherapy would induce remission and the patient would have chronic phase cells reinfused. Although this is an attractive notion in theory, resistance of the disease to chemotherapeutic agents has prevented this strategy from being successful. ${ }^{9}$ During the 1980 s, despite sibling donor transplants being the treatment of choice, some exploratory studies were undertaken using autografting for CML while
Accepted for publication 11 November 1997 


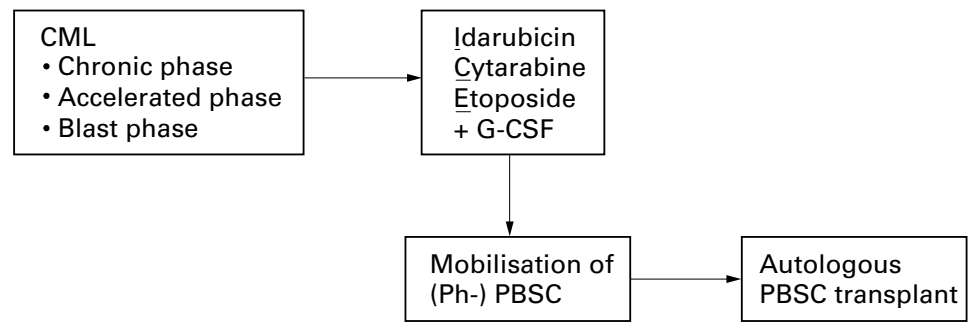

Figure 1 Approach adopted by Carella for autografting in CML. Initially mobilising late in disease, progression with ICE, but better results obtained by autografting in earlier chronic phase. removed from the transplant-the relative risk of relapse was 5.4 times ( $\mathrm{p}$ value of $<0.0001) .^{12}$ $\mathrm{T}$ cell depletion is an effective way of controlling or preventing graft versus host disease following allogeneic bone marrow transplant, but in CML these benefits are offset by the increased relapse risk. Among patients who had received a $\mathrm{T}$ cell depleted bone marrow transplant results showed that those who had no acute graft versus host disease at all had an especially high rate of relapse. ${ }^{13}$ Importance of $\mathrm{T}$ lymphocytes for the maintenance of remission following transplantation for CML was confirmed when it proved possible to reinduce remission by infusing lymphocytes from the original donor. ${ }^{14}$ It is also possible to achieve a similar effect by sudden cessation of immunosuppressive treatment, thereby releasing immune competent cells into the circulation. ${ }^{15} 16$

In the 1990s Carella and colleagues in Genoa, Italy, gave autografting in CML a new lease on life when they found that patients with CML regenerated with wholly, or more usually partially, Philadelphia negative haemopoiesis following intensive chemotherapy. ${ }^{17}{ }^{18}$ This followed the observation that there was evidence of residual Philadelphia negative cells in many patients with CML, at least in the early stages of their disease. ${ }^{19}{ }^{20}$ Although the Philadelphia negativity was generally not sustained, Carella's group showed that it was possible, in the early recovery phase, to collect sufficient Philadelphia negative haemopoietic progenitor cells from peripheral blood to perform a subsequent autologous transplant (fig 1).

They used a highly intensive chemotherapy regimen of idarubicin $8 \mathrm{mg} / \mathrm{m}^{2} /$ day iv push on days $1-5$, cytarabine $800 \mathrm{mg} / \mathrm{m}^{2}$ two hour infusion daily on days $1-5$, and etoposide $150 \mathrm{mg} /$ $\mathrm{m}^{2}$ two hour infusion daily on days $1-3 .{ }^{21}$ The haemopoietic growth factor granulocyte colony stimulating factor was used to stimulate recovery of the neutrophils before peripheral blood stem cell collection. Carella's initial series involved accelerated phase or blast crisis patients and although a significant proportion converted to Philadelphia negativity this was transient and all patients eventually relapsed. They subsequently moved on to explore the possibility of using this approach in 23 patients who were in chronic phase. Twenty of those were Philadelphia negative in blood after mobilisation and they engrafted well; seven remained Philadelphia negative two to 45 months after transplantation. Within this group of patients only three have died, none directly related to the transplant. ${ }^{22}$

Other groups took up the challenge to reproduce these findings. Our own group used a modified version of the Carella protocol in which only idarubicin and cytarabine were given to the patient. It was possible to collect peripheral blood stem cells from 23 of 41 patients from five centres who underwent this regimen that had either a complete or a major ( $<35 \%$ Philadelphia positive) cytogenetic response. A proportion of patients were also negative by Southern blotting but all patients were positive using polymerase chain reaction for bcr-abl. This study showed that there was 


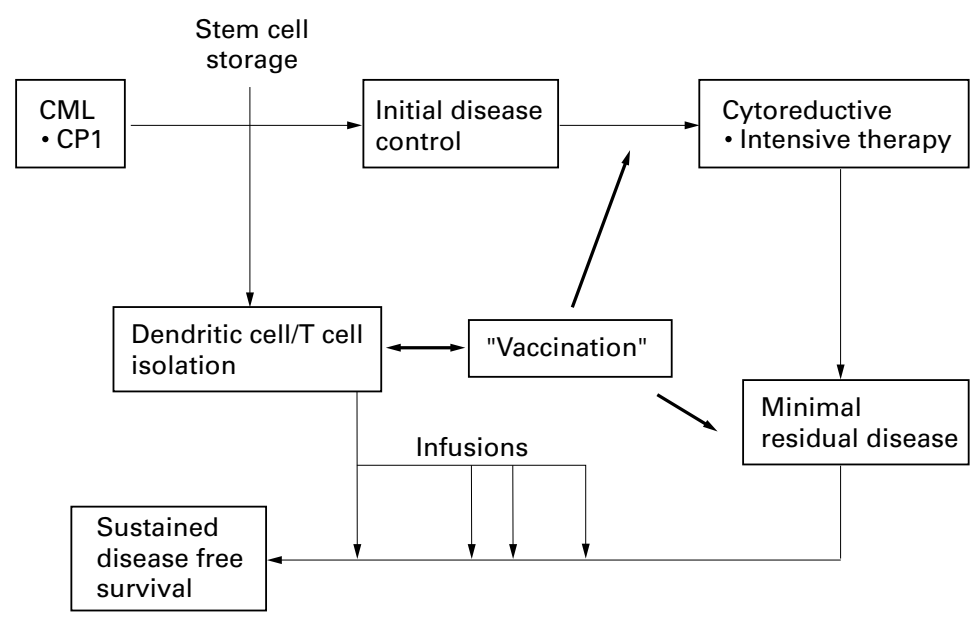

Figure 2 One potential therapeutic option involves harvesting cells in first chronic phase (CP1) and obtaining disease control by conventional chemotherapeutic means. This treatment would be augmented by vaccinating against bcr-abl thereby inducing an immune response against the malignant clone that could be further augmented by return of in vitro manipulated lymphocytes directed against bcr-abl.

an important effect of duration of chronic phase on the likelihood of being able to collect sufficient Philadelphia negative cells. Of 11 patients treated in the first 12 months of chronic phase, 10 obtained a complete or major response, whereas only 13 of $30(43 \%)$ did so after a chronic phase exceeding one year. $^{23}$

One problem with peripheral stem cells collected in this way is that their quality is often poor-that is, the number of colony forming units and CD34 positive cells is often relatively few. Of 28 patients in our series who underwent autologous peripheral blood stem cell transplants three died within six months of the procedure. Nineteen remain alive with three in accelerated phase, three with quiescent disease on no treatment, and the rest alive in first chronic phase receiving hydroyxurea with or without $\alpha$ interferon. Median survival following transplant is still only 24 months although median survival from diagnosis in this highly selected series of patients is 55 months.

\section{When to autograft?}

It is clear that there is a case to be made for autografting as early treatment in chronic myeloid leukaemia. Most people would prefer to control the patient's white count with a drug such as hydroxyurea before proceeding to intensive treatment, rather than give high dose chemotherapy straight away. What is clear is that autografting in CML remains an experimental procedure the benefits of which are unknown. It is therefore important that any patients who receive such treatment should be within a trial or study in which the outcome is capable of being assessed. Ideally this would be in a randomised controlled trial such as the study being undertaken by the UK Medical Research Council in its CML IV trial. This trial is comparing a course of intensive treatment (idarubicin and cytarabine) followed by a bone marrow transplant following recovery from the intensive treatment with continuing interferon. The doses of chemotherapy, the transplant conditioning, and cells to rescue the patients from that conditioning have all been carefully chosen to minimise mortality and reduce morbidity. Suitable patients are those with no compatible sibling, or those too old for a sibling allograft and yet fit enough for intensive treatment. In our institution this would include all patients over the age of 60 who are fit and some patients between the ages of 50 and 60 . It would be inappropriate to advise patients that they could have an autograft, with intensive conditioning such as high dose busulphan, and then at some later date be considered fit for unrelated donor transplant using similar or more intensive conditioning. It is important to give patients complete advice and make a decision as to the appropriate management at the beginning. Within the MRC trial patients receive their chemotherapy followed by the autograft starting three months from diagnosis after an initial trial of $\alpha$ interferon. ${ }^{24}$ Other national and international trials are investigating earlier autografting and/or the use of peripheral blood stem cell autografts.

There are few data on the optimal drugs and dosage regimens for the initial priming chemotherapy. We also do not know which growth factor or growth factor combinations are the most appropriate for mobilisation.

Other important issues to be considered in autologous transplantation relate to purging - a technique by which overt or potential malignant cells are removed from the transplant inoculum. At present such procedures are highly experimental and none has so far been proved effective. Deisseroth's group has shown, using gene marking studies, that malignant cells in the CML rescue marrow do contribute to relapse although this is not the same as saying that they cause the relapse. ${ }^{25}$

\section{The future}

It seems clear that increasingly intensive treatment for CML is not the whole answer. Despite sterling work by many groups around the world we will still benefit from improved understanding of the Philadelphia positive progenitor cells, in terms of biology and susceptibilities to specific means of disruption. Ideally autografts should stimulate the graft versus leukaemia effect. Techniques under consideration include dendritic cell or $\mathrm{T}$ lymphocyte infusions, prior vaccination against bcr-abl protein products, ${ }^{26}$ and, in the more distant future, DNA or RNA vaccines. Some pilot studies of antisense gene treatment targeted at blocking the bcr-abl locus have also been attempted although reproducibility remains a problem. ${ }^{27}$ Other target genes such as c-myb are also being investigated. ${ }^{28}$ Improved vectors and delivery systems appear likely to be required for gene therapy before antisense is likely to have a role in CML. ${ }^{29}$

One view of the future would be to modify the schema proposed over 20 years ago by Spiers. ${ }^{9}$ Patients would, following diagnosis, have stem cells collected from which dendritic cells or specific $\mathrm{T}$ cell subsets would be isolated and amplified. Such cells together with unmanipulated stem cells could then be frozen for future use. Initial disease control would be 
achieved following which some form of cytoreduction (possibly with intensive treatment or $\alpha$ interferon) would be done until the patient had minimal residual disease - that is, disease that could not be detected conventionally. They may previously have been vaccinated against bcr-abl and could again be vaccinated once the disease was in a form of remission. Further maintenance of sustained disease free survival would be achieved by repeated infusions of dendritic cell and $T$ cell combinations primed to seek out and destroy those cells with the bcr-abl gene expression. Stem cells to reestablish haemopoiesis may indeed be unnecessary (fig 2).

Allografting remains the treatment of choice when practical. If an allogeneic donor is unavailable autografts are currently a viable alternative and by preference should be performed early. This appears to induce a prolonged chronic phase, but the role of autografting in achieving a "cure" may be by returning selected and manipulated host cells capable of re-establishing a Philadelphia negative haemopoiesis and eliminating any Philadelphia positive clones with a graft versus leukaemia effect.

1 Talpaz M, Kantarjian H, Kurzrock R. Interferon-alpha produces sustained cytogenetic responses in chronic myelogenous leukemia. Ann Intern Med 1991;114:532-8.

2 Italian Cooperative Study Group on Chronic Myeloid Leukaemia. Interferon alpha-2a as compared with conventional chemotherapy for the treatment of chronic myeloid leukaemia. N Engl f Med 1994;330:820-5.

3 Allan NC, Shepherd PCA, Richards SM. UK Medical Research Council randomised multi centre trial on interferon-alpha $\mathrm{n} 1$ for chronic myeloid leukaemia: improved survival irrespective of cytogenetic response. Lancet proved survival irrest

4 Thaler J, Fluckinger T, Huber $\mathrm{H}$, et al. Treatment of 11 Thaler J, Fluckinger $\mathrm{T}$, Huber $\mathrm{H}$, et al. Treatment of 11 patients with chronic myelogenous leukaemia with interferon-alpha-2C and

5 Guilhot F, Chastang C, Guerci A, et al. Interferon alpha 2b (IFN) and cytarabine (Ara-C) increase survival and cytogenetic response in chronic myeloid leukemia (CML). Results of a randomized trial [abstract]. Blood 1996; 88(suppl 1): 141a

6 Thomas ED, Clift RA, Fefer A, et al. Marrow transplantation for the treatment of chronic myelogenous leukemia. Ann Intern Med 1986;104:155-63.

7 Kantariian HM, Deisseroth A, Kurzrock R, et al. Chronic myeloid leukemia: a concise update, Blood 1993;82:691703 .

8 Speiser DE, Tiercy JM, Rufer N, et al. High resolution HLA matching associated with decreased mortality after unrelated bone marrow transplantation. Blood 1996;87:4455lated 62 .

9 Spiers AS. The treatment of chronic granulocytic leukaemia. Br f Haematol 1976;32:291-8.

10 Brito-Babapulle F, Bowcock SJ, Marcus RE, et al. Autografting for patients with chronic myeloid leukaemia in chronic phase: peripheral blood stem cells may have a finite capacity for maintaining haemopoiesis. Br F Haematol 1989;73:76-81.
11 McGlave PB, De Fabritiis P, Deisseroth A, et al. Autologous transplant therapy for chronic myeloid leukaemia prolongs survival: results from eight transplant groups. Lancet 1994; 343:1486-91

12 Goldman JM, Gale RP, Horowitz MM, et al. Bone marrow transplantation for chronic myelogenous leukaemia in chronic phase. Increased risk of relapse with T-cell depletion. Ann Intern Med 1988;108:806-14.

13 Apperley JF, Mauro FR, Goldman JM, et al. Bone marrow transplantation for chronic myeloid leukaemia in first chronic phase: importance of a graft-versus-leukaemia effect. Br $\mathcal{F}$ Haematol 1989;69:239-45

14 Kolb HJ, Mittermuller J, Clemm Ch, et al. Donor leukocyte transfusions for treatment of recurrent chronic myelogenous leukemia in marrow transplant patients. Blood 1990; 76:2462-5.

15 Collins RH Jr, Rogers ZR, Bennett M, et al. Hematologic relapse of chronic myelogenous leukemia following allogeneic bone marrow transplantation: apparent graft versus leukemia effect following abrupt discontinuation of immunosuppression. Bone Marrow Transplant 1992;10:391-5.

16 Odom LF, August CS, Githens JH, et al. Remission of relapsed leukaemia during a graft versus host reaction. A "graft-versus-leukaemia reaction" in man? Lancet 1978;ii: "graft-verst.

17 Carella AM, Pollicardo N, Pungolino E, et al. Mobilization of cytogenetically "normal" blood progenitor cells by intensive conventional chemotherapy for chronic myeloid and acute lymphoblastic leukemia. Leuk Lymphoma 1993; 9:477-83.

18 Carella AM, Podesta M, Frassoni F, et al. Selective overshoot of Ph-negative blood haemopoietic cells after intensive idarubicin containing regimen and their repopulating capacity after reinfusion. Stem Cells 1993;11(suppl 3): $67-72$

19 Butturini A, Keating A, Goldman JM, et al. Autotransplants in chronic myeloid leukaemia. Lancet 1990;335:1255-8.

20 Leemhuis T, Leibowitz D, Cox G, et al. Identification of BCR-ABL negative primitive haemopoietic cells within chronic myeloid leukaemia marrow. Blood 1993;81:801-7.

21 Carella AM, Frassoni F, Pollicardo N, et al. Philadelphia chromosome negative peripheral blood stem cells can be mobilized in the early phase of recovery after a myelosuppressive chemotherapy in Philadelphia positive acute lymphoblastic leukaemia. Br f Haematol 1995;89:535-8.

22 Carella AM, Chimirri F, Podesta $M$, et al. High-dose chemo-radiotherapy followed by autologous Philadelphia chromosome-negative blood progenitor cell transplantation in patients with chronic myelogenous leukemia. Bone Marrow Transplant 1996;17:201-5.

23 Chalmers EA, Franklin IM, Kelsey SM, et al. Treatment of chronic myeloid leukaemia in first chronic phase with idarubicin \& cytarabine; mobilization of philadelphia negative peripheral blood stem cells. Br F Haematol 1997;96:62734.

24 Spencer A, O'Brien SG, Goldman JM. Options for therapy in chronic myeloid leukaemia. Br F Haematol 1995;91:2-7.

25 Deisseroth $\mathrm{AB}, \mathrm{Zu} \mathrm{Z}$, Claxton $\mathrm{D}$, et al. Genetic marking shows that $\mathrm{Ph}+$ cells present in autologous transplants of chronic myelogenous leukemia (CML) contribute to relapse after autologous bone marrow in CML. Blood 1994;83:3068-76.

26 Bosch GJ, Joosten AM, Kessler JH, et al. Recognition of BCR-ABL positive leukemic blasts by human CD4+ T cells elicited by primary in vitro immunization with a BCR-ABL breakpoint peptide. Blood 1996;88:3522-7.

27 O'Brien SG, Kirkland MA, Melo JV, et al. Antisense BCRABL oligomers cause non-specific inhibition of chronic myeloid leukaemia cell lines. Leukemia 1994;8:2156-62.

28 Szczylik C, Skorski T, Malaguarnera L, et al. Inhibition of in-vitro proliferation of chronic myelogenous leukaemia progenitor cells by c-myb antisense oligonucleotides. Folia Histochem Cytobiol 1996;34:129-34.

29 Tari A, Khodadadian M, Ellerson D, et al. Liposomal delivery of oligonucleotides. Leuk Lymphoma 1996;21:93-7. 